\title{
A mini-review on organic synthesis in water
}

\begin{abstract}
The use of water as solvent in organic synthesis is one of the most powerful tool of green chemistry as it reduces emission of toxic chemicals in the environment thereby reducing pollution. Reactions can be carried out under mild conditions minimizing chemical waste with easy work up procedure enabling recycling of the catalyst. This review briefly highlights some important reactions carried out recently in water.
\end{abstract}

Keywords: green chemistry, water, organic synthesis, green solvent

\author{
Volume I Issue 7 - 2017
}

Harshita Sachdeva, Sarita Khaturia

Department of Chemistry, Mody University of Science and

Technology, India

Correspondence: Harshita Sachdeva, Department of Chemistry, College of Arts, Science and Humanities, Mody University of Science and Technology, Laxmangarh-3323II (Sikar), Rajasthan, India, Email drhmsachdevaster@gmail..com, harshitasachdeva.cash@modyuniversity.ac.in

Received: December 3, 2017 | Published: December 13,2017

\section{Introduction}

Organic synthesis in water has attracted the attention of chemists for many years. Water is the nature's solvent and possesses distinguished physical and chemical properties. It exhibits powerful hydrogen bonding and wide temperature range to remain in liquid state. In recent years, many organic transformations have been carried out in water. ${ }^{1,2}$ Many organic solvents like benzene, methanol, toluene are carcinogenic and can be toxic to human health and cause an environmental menace by polluting the atmosphere. The replacement of volatile organic solvents in organic reaction is an important aim of green chemistry., Earliest known examples of organic synthesis in water include Wohler's urea synthesis and Baeyer and Drewsen's indigo synthesis..$^{5-7}$

In recent years, several $\mathrm{N}, \mathrm{O}$, and $\mathrm{S}$ containing heterocyclic compounds are synthesized employing green synthetic protocols. It is of considerable interest to learn more about varied green technology platforms, which have been utilized for the synthesis of important heterocyclic scaffold. Being an important and growing area of research, these green protocols have been regularly reviewed. The present attempt is to review briefly water mediated organic reactions, resulting in the synthesis of various heterocyclic frame works and to highlight the significance as well as utility of water as a green solvent.

\section{Synthesis of substituted azo schiff bases ${ }^{8}$}

Zarei $\mathrm{M}$ et al. ${ }^{8}$ reported the synthesis of pure azo Schiff bases (2) in high yields by mixing of the reagents either as aqueous slurry or by grinding at room temperature. Azoaldehyde (1) was prepared from p-anisidine and 2-hydroxy-3-methoxybenzaldehyde (o-vanillin) in aqueous medium at $0-5^{\circ} \mathrm{C}$ and then 1 was allowed to react with amines in a small amount of water at room temperature to produce azo Schiff bases (2) in excellent yields (Figure 1).

\section{Synthesis of pyrano[2,3-c]pyrazoles 9}

Silica-water reaction medium was applied by Pravin et al. ${ }^{9}$ for the synthesis of various pyrano[2,3-c]pyrazole derivatives based on the adsorptive nature of silica. The reaction was carried out under mild and neutral conditions accepting several functional groups present in the molecules thus reducing the possibility of many unwanted side reactions. Present method offers marked improvements with regard to product yield, reaction time, and greenness of procedure, avoiding hazardous organic solvents/toxic catalysts and provides a better, clean and practical alternative to the existing protocols (Figure 2).

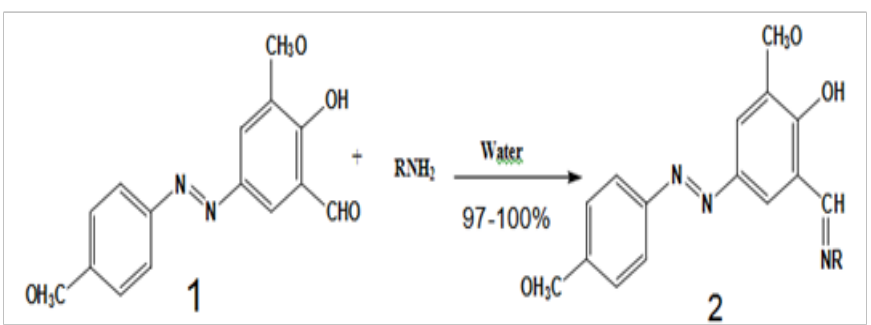

Figure I Synthesis of substituted azo Schiff bases. ${ }^{8}$<smiles>CCOC(=O)CC(C)=[13C]C(C)[14C](=O)OCC</smiles>

Figure 2 Synthesis of Pyrano[2,3-c]pyrazoles. ${ }^{9}$

\section{Synthesis of aryldipyrromethanes ${ }^{10}$}

Taoufik et al. ${ }^{10}$ have reported the oxidation of aryldipyrromethanes with p-chloranil (in dichloromethane), or DDQ (2,3-dichloro5,6-dicyano-1,4-benzoquinone) at room temperature to obtain the corresponding dipyrrins in good yields (50-78\%) (Figure 3).

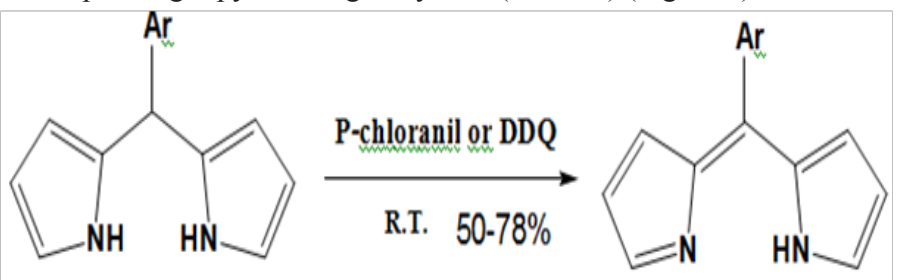

Figure 3 Synthesis of aryldipyrromethanes. ${ }^{10}$

\section{Synthesis of pyrimido[4,5-d]pyrimidine"}

A practically convenient and eco-friendly aqua mediated synthesis of pyrimido[4,5-d]pyrimidines by the reaction of barbituric acid, aldehyde and urea or thiourea to yield pyrimido[4,5-d]pyrimidines 
has been developed by Kidwai et al. ${ }^{11}$ without using any catalyst and hazardous organic solvents and corrosive acids or bases. Waterinsoluble solid products obtained in short time are found to be essentially pure and in very high yield (Figure 4).<smiles>[R]CO[NH2+]C(N)=O</smiles>

Figure 4 Synthesis of Pyrimido[4,5-d]pyrimidine."

\section{Synthesis of 2-aminothiazoles ${ }^{12}$}

A highly efficient and facile method has been described by Taterao et al. ${ }^{12}$ for the synthesis of substituted 2-aminothiazoles in water without any added catalyst or co-organic solvent. The reaction was carried out at ambient temperature and the products were obtained in excellent isolated yields. The developed protocol is successfully applied for the preparation of an anti-inflammatory drug, fanetizole (Figure 5).

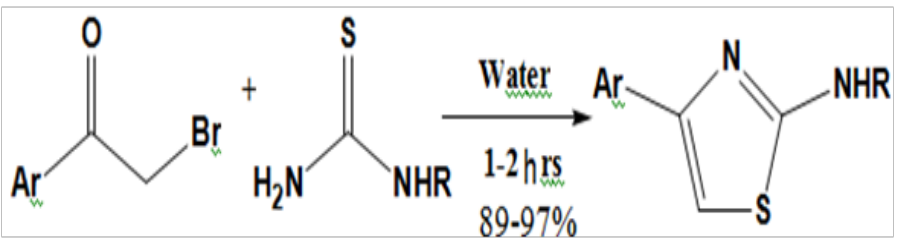

Figure 5 Synthesis of 2-aminothiazoles. ${ }^{12}$

\section{Synthesis of alkyl or aryl-I4H-dibenzo [a, j]xanthe-} nes $^{13}$

Alkyl- or aryl-14H-dibenzo [a,j]xanthene derivatives were synthesized efficiently by the reaction of beta-naphthol and aliphatic and aromatic aldehydes in the presence of $\mathrm{KAl}\left(\mathrm{SO}_{4}\right)_{2} \mathrm{x}_{12} \mathrm{H}_{2} \mathrm{O}$ (alum) under aqueous condition at $100^{\circ} \mathrm{C}$ by Dabiri et al. ${ }^{13}$ Different types of aromatic and aliphatic aldehydes were used in the reaction and in all cases the products synthesized successfully. Several solvents were examined for this reaction; however, in terms of reaction yield and time, water was found to be the optimum solvent (Figure 6).

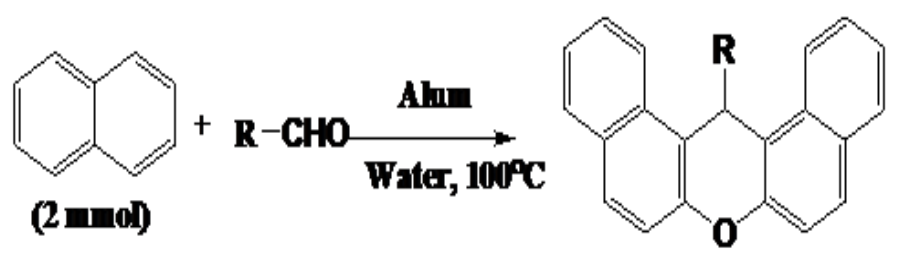

Figure 6 Synthesis of alkyl or aryl- |4H-dibenzo [a, j]xanthenes. ${ }^{13}$

Syntheses of $\mathbf{N}$-azacycloalkanes, pyrazole, pyrazolidine, and phthalazine derivatives ${ }^{14}$

$\mathrm{Ju}$ et $\mathrm{al}^{14}$ have reported the synthesis of nitrogen-containing heterocycles from alkyl dihalides (ditosylates) and primary amines and hydrazines via a simple and efficient cyclocondensation in an alkaline aqueous medium that occurs under microwave irradiation. This improved greener synthetic methodology provides a simple and straightforward one-pot approach to the synthesis of a variety of heterocycles, such as substituted azetidines, pyrrolidines, piperidines, azepanes, N-substituted 2,3-dihydro-1H-isoindoles, 4,5-dihydropyrazoles, pyrazolidines, and 1,2-dihydrophthalazines (Figure 7).

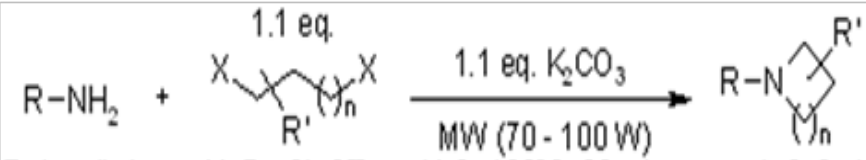

$$
\begin{aligned}
& \text { R: Ar, alkyl } \quad X: B r, C l, O T s \quad H_{2} 0,120^{\circ} \mathrm{C}, 20 \text { min } \quad n: 1,2,3,4
\end{aligned}
$$

Figure 7 Syntheses of N-Azacycloalkanes, Pyrazole, Pyrazolidine, and Phthalazine derivatives. ${ }^{14}$

\section{Synthesis of pyrazoles and diazepines ${ }^{15}$}

Polshettiwar et al.${ }^{15}$ have reported an expeditious room temperature synthesis of pyrazoles and diazepines by condensation of hydrazines/ hydrazides and diamines with various 1, 3-diketones. This greener protocol was catalyzed by polystyrene supported sulfonic acid (PSSA) and preceded efficiently in water in the absence of any organic solvent within 1-2 $\min$ (Figure 8).<smiles>[R]C(=O)C([X])C(C)=O</smiles>

Figure 8 Synthesis of pyrazoles and diazepines. ${ }^{15}$

Synthesis of Substituted 3,4-dihydropyrimidin-2(I H)-ones ${ }^{16}$

An environmentally benign aqueous Biginelli protocol for the synthesis of substituted 3,4-dihydropyrimidin-2(1H)-ones using polystyrenesulfonic acid (PSSA) as a catalyst has been achieved by Polshettiwar et al. ${ }^{16}$ These microwave-assisted reactions proceed efficiently in water in the absence of organic solvent, with simple filtration as the product isolation step (Figure 9).<smiles>[R]OC(=O)CC(C)=O</smiles>

Figure 9 Synthesis of substituted 3,4-dihydropyrimidin-2(IH)-ones. ${ }^{16}$

\section{Synthesis of 1,3 dioxanes ${ }^{17}$}

A novel tandem bis-aldol reaction of ketone with paraformaldehyde catalyzed by polystyrenesulfonic acid is reported by Polshettiwar et al. ${ }^{17}$ in aqueous medium to yield 1,3-dioxanes. This one-pot, operationally simple microwave-assisted synthetic protocol proceeds efficiently in water in the absence of any organic solvent, with excellent yield (Figure 10).

Synthesis of methyl 6-amino-5-cyano-4-aryl-2,4-dihydropyrano[2,3-c] pyrazole-3-carboxylates ${ }^{18}$

A green and efficient one-pot, four-component synthesis of methyl 6-amino-5-cyano-4-aryl-2, 4-dihydropyrano [2, 3-c] pyrazole-3carboxylates in water is reported by Adeleh et al. ${ }^{18}$ The method is 
catalyst-free, atom-economical, and does not involve tedious work-up or purification affording the target compounds in good yields (Figure $11)$.<smiles>O=C1CC(c2ccccc2)C(=O)c2ccccc2C1=O</smiles>

Figure 10 Synthesis of I, 3 dioxanes. ${ }^{17}$

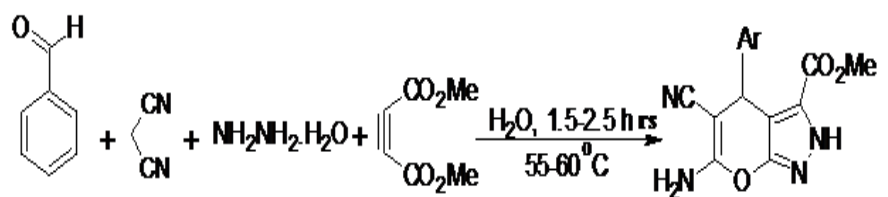

Figure I I Synthesis of methyl 6-amino-5-cyano-4-aryl-2,4dihydropyrano[2,3-c] pyrazole-3-carboxylates. ${ }^{18}$

\section{Synthesis of coumarins ${ }^{19}$}

A simple and convenient method for the efficient synthesis of coumarins in water catalyzed by $\mathrm{K}_{2} \mathrm{CO}_{3}$ is developed by Rehanaanjum. ${ }^{19}$ Optimal result was obtained using $20 \mathrm{~mol} \%$ of $\mathrm{K}_{2} \mathrm{CO}_{3}$. The experiment was conducted with phenolic substrate and $\beta$-keto ester in the presence of catalytic amount of $\mathrm{K}_{2} \mathrm{CO}_{3}(20 \mathrm{~mol} \%)$ in water. The reaction proceeded spontaneously at ambient temperature and was completed within $1 \mathrm{hr}$. The precipitated solid was filtered, dried and washed with $20 \%$ ethyl acetate in petroleum ether to afford coumarins (Figure 12).
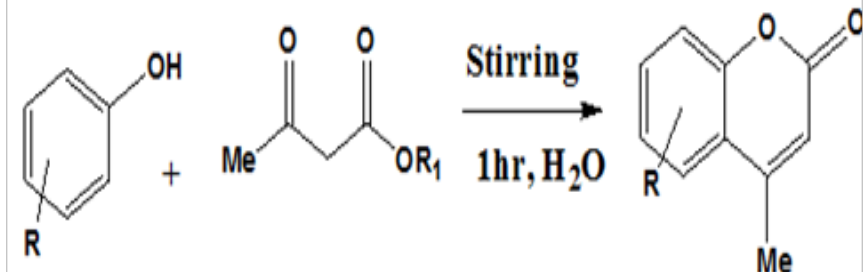

Figure 12 Synthesis of Coumarins. ${ }^{19}$

Synthesis of 2-amino-4-(5-hydroxy-3-methyl- I H-pyrazol-4-yl)-4H chromene-3-carbonitrile derivatives ${ }^{20}$

Kumaravel et al. ${ }^{20}$ have developed a catalyst-free combinatorial library of novel 2-amino-4-(5-hydroxy-3-methyl-1H-pyrazol4-yl)-4H-chromene-3-carbonitrile derivatives by the reaction of hydrazine hydrate, ethyl acetoacetate, 2-hydroxybenzaldehydes and malononitrile in water at ambient temperature (Figure 13).<smiles>O=Cc1ccccc1</smiles><smiles>CCOC(=O)CC(C)=O</smiles><smiles>Cc1n[nH]c(O)c1C1C(C#N)=C(N)Oc2ccccc21</smiles>

Figure 13 Synthesis of 2-amino-4-(5-hydroxy-3-methyl- I H-pyrazol-4-yl)4 Hchromene-3- carbonitrile derivatives. ${ }^{20}$

\section{Synthesis of spiroindoline-pyranopyrazoles ${ }^{21}$}

Ahadi et al. ${ }^{21}$ have reported the synthesis of spiro[indoline-3,4'- pyrano[2,3-c]pyrazole]-5'-carbonitriles with high yields and purity by the one-pot, four-component reaction of $\beta$-ketoesters, hydrazine hydrate, malononitrile, and isatins in aqueous media at room temperature (Figure 14).

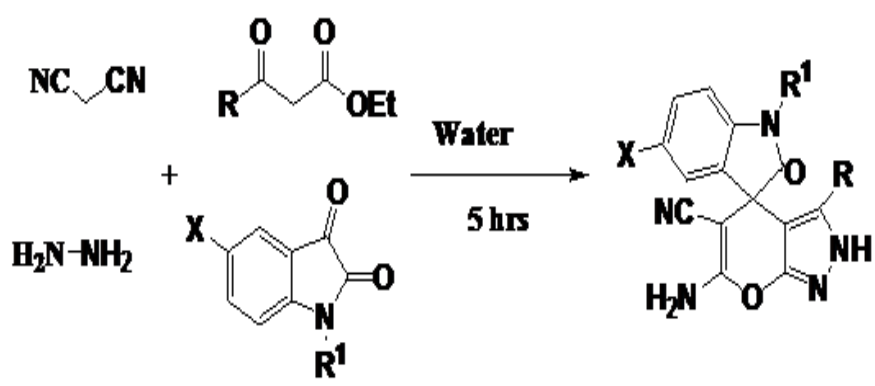

Figure I4 Synthesis of spiroindoline-pyranopyrazoles. ${ }^{21}$

\section{Synthesis of 2-amino-I, 3, 4-thiadiazoles ${ }^{22}$}

Aryanasab $\mathrm{F}$ et al. ${ }^{22}$ have reported a new and facile protocol for the synthesis of 2-amino-1,3,4-thiadiazoles in water by the reaction of acid hydrazides with dithiocarbamates in moderate to excellent yields (Figure 15).

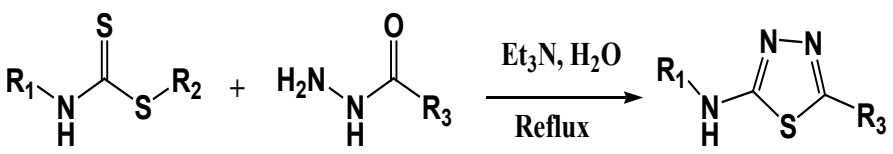

Figure 15 Synthesis of 2-amino-I, 3, 4-thiadiazoles ${ }^{22}$

\section{Synthesis of novel thiochromone-annulated thiopyra- nocoumarin derivatives ${ }^{23}$}

Moghaddam et al. ${ }^{23}$ have reported an efficient catalyst-free synthesis of novel pentacyclic thiochromone-annulated thiopyranocoumarin derivatives via domino Knoevenagel-hetero-Diels-Alder reaction of 4-hydroxy dithiocoumarin and O-acrylated salicylaldehyde derivatives in $\mathrm{H}_{2} \mathrm{O}$ as solvent. The products are formed in good yields with high regio- and stereo-selectivity (Figure 16).

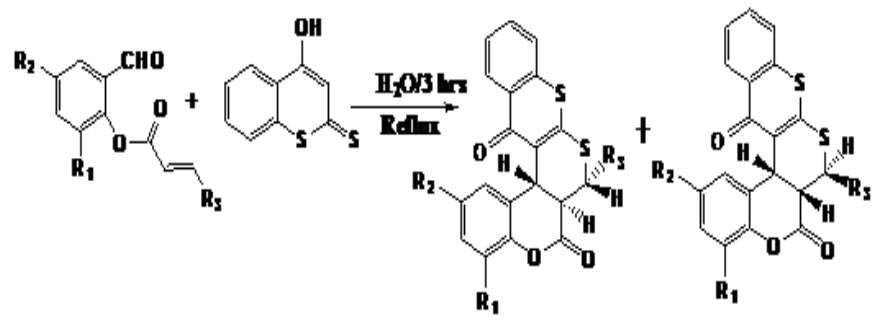

Figure 16 Synthesis of novel thiochromone-annulated thiopyranocoumarin derivatives. ${ }^{23}$

Synthesis of 3, 4-dihydroquinoxalin-2-amine derivatives $^{24}$

A simple and efficient one-pot synthetic approach for the preparation of biologically interesting 3,4-dihydroquinoxalin-2amine derivatives using EDTA-catalyzed three component reactions of o-phenylenediamines, carbonyl compounds, and isocyanides in an aqueous medium is described by Kolla et al. ${ }^{24}$ This method is of great value because of its environmentally benign character, high yields, and ease of handling (Figure 17).

Synthesis of substituted fused thiazole derivatives ${ }^{25}$

Alison et al. ${ }^{25}$ have reported that hetero-cycloisomerization 
reactions of propargylic alcohol derivatives leading to indolizines have been demonstrated to proceed in the presence of water alone. This stands as a significant advance over the previous methods using $\mathrm{Pt}, \mathrm{Cu}$ or $\mathrm{Ag}$ salts paired with ligands in organic solvents such as benzene, acetonitrile or methylene chloride (Figure 18).

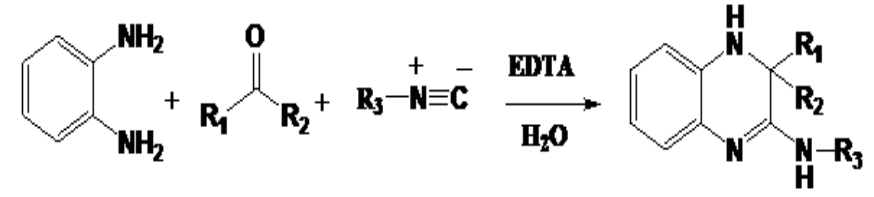

Figure I 7 Synthesis of 3, 4-dihydroquinoxalin-2-amine derivatives. ${ }^{24}$
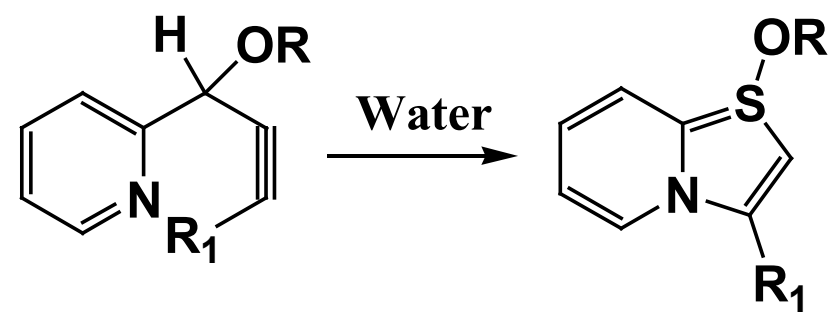

Figure 18 Synthesis of substituted fused thiazole derivatives. ${ }^{25}$

Gawande ${ }^{26}$ provided a brief overview of some selective catalystfree reactions in aqueous media. ${ }^{26}$ Further, many organic molecules are partially soluble in water and reactions that appear as heterogeneous mixtures and suspensions may involve on-water and in-water reaction modes occurring simultaneously. Organic synthesis reactions on water at the organic-liquid water interface were studied by Butler et al. ${ }^{27}$ García-García et al. ${ }^{28}$ have reported the preparation of a mesoscopic metal-organic structure based on single-layer assembly of aluminium chains and organic alkylaryl spacers. The material markedly accelerates condensation reactions in water in the absence of acid or base catalyst, as well as organocatalytic Michael-type reactions that also show superior enantioselectivity when comparing with the host-free transformation. ${ }^{28}$ Alaoui et al. ${ }^{29}$ have reported the ultrasound assisted facile one pot synthesis of sulfonamide-isoxazoles using cerium (IV) ammonium nitrate (CAN) as an efficient oxidant in aqueous medium. ${ }^{29}$ Dilauro et al. ${ }^{30}$ have reported the nucleophilic additions of highly polar organometallic compounds to imines and nitriles using water as a reaction medium. ${ }^{30}$ They reported that the addition of highly polar organometallic compounds to non-activated imines and nitriles proceeds quickly, efficiently, and chemoselectively with a broad range of substrates at room temperature and under air with water as the only reaction medium.

\section{Conclusion}

In this review article, we have focused on some aqua mediated organic transformations which will surely help scientists and researchers across the globe to develop new inexpensive, clean and environmentally benign strategies to carry out organic synthesis.

\section{Acknowledgements}

The authors are thankful to the Dean, Prof. Atul Kumar, CASH, MUST, Laxmangarh (Sikar), Rajasthan, India for providing support and necessary research facilities in the department.

\section{Conflict of interest}

The author declares no conflict of interest.

\section{References}

1. Ren Y, Cai C. Iodine Catalysis in Aqueous Medium: An Improved Reaction System for Knoevenagel and Nitroaldol Condensation. Catal Lett. 2007;118(1-2):134-138.

2. Gong K, He ZW, Xu Y, et al. Green synthesis of 5-benzylidene rhodanine derivatives catalyzed by $1-$ butyl-3-methyl imidazolium hydroxide in water. Monatsh Chem. 2008;139(8):913-915.

3. Mikami K. Green Reaction Media in Organic Synthesis. UK: Blackwell Publishing Ltd; 2005.

4. Tanaka K. Solvent-Free Organic Synthesis. Germany: Wiley-VCH; 2004.

5. Li CJ. Organic reactions in aqueous media with a focus on carbon-carbon bond formations: a decade update. Chem Rev. 2005;105:3095-3165.

6. Darryl CR, Breslow R. Hydrophobic acceleration of Diels-Alder reactions. J Am Chem Soc. 1980;102(26):7816-7817.

7. Grieco PA. Organic synthesis in water. UK: Blacky Academic and Professional; 1988.

8. Zarei M, Jarrahpour A. Green and efficient synthesis of azo Schiff bases. Iranian J Sci \& Tech. 2011;A3:235-242.

9. Pravin V, Shinde JB, Gujar B, et al. Silica in Water: A Potentially Valuable Reaction Medium for the Synthesis of Pyrano [2,3-c]pyrazoles. Bull Kor Chem Soc. 2012;33(4):1345-1348.

10. Rohand T, Dolusic E, Ngo TH, et al. Efficient synthesis of aryldipyrromethanes in water and their application in the synthesis of corroles and dipyrromethenes. ARKIVOC. 2007;2007(X):307-324.

11. Kidwai M, Singhal K, Kukreja S. One-pot Green Synthesis for Pyrimido [4,5-d]pyrimidine Derivatives. Naturforsch. 2007;62b:732-736.

12. Taterao MP, Ingale SA, Srinivasan KV. Catalyst-free efficient synthesis of 2-aminothiazoles in water at ambient temperature. Tetrahedron. 2008;64(22):5019-5022.

13. Dabiri M, Baghbanzadeh M, Nikcheh MS, et al. Eco-friendly and efficient one-pot synthesis of alkyl- or aryl-14H-dibenzo[a,j]xanthenes in water. Bioorg Med Chem Lett. 2008;18(1):436-438.

14. Ju Y, Varma RS. Aqueous $\mathrm{N}$-heterocyclization of primary amines and hydrazines with dihalides: microwave-assisted syntheses of N-azacycloalkanes, isoindole, pyrazole, pyrazolidine, and phthalazine derivatives. J Org Chem. 2006;71(1):135-141.

15. Polshettiwar V, Varma RS. Greener and rapid access to bio-active heterocycles: room temperature synthesis of pyrazoles and diazepines in aqueous medium. Tetrahedron Lett. 2008;49(2):397-400.

16. Polshettiwar V, Varma RS. Biginelli reaction in aqueous medium: a greener and sustainable approach to substituted 3,4-dihydropyrimidin -2(1H)-ones. Tetrahedron Lett. 2007;48(41):7343-7346.

17. Polshettiwar V, Varma RS. Tandem bis-aldol sreaction of ketones: a facile one-pot synthesis of 1, 3-dioxanes. J Org Chem. 2007;72(19):7420 7422 .

18. Adeleh MZ, Issa E, Hamid RK. A green and convenient approach for the synthesis of methyl 6-amino-5-cyano-4-aryl-2,4-dihydropyrano[2,3-c]pyrazole-3-carboxylates via a one-pot, multi-component reaction in water. Tetrahedron Lett. 2012;53(41):5519-5522.

19. Rehanaanjum R. A simple and eco friendly synthesis of Coumarins. Golden Research Thoughts. 2012;2(3):1-4.

20. Kumaravel K, Vasuki V. Four component catalyst-free reaction in water synthesis of novel 2-amino-4-(5-hydroxy-3-methyl-1H-pyrazol-4-yl)-4H chromene-3 carbonitrile derivatives. Green Chem. 2009;11(12):1945-1947. 
21. Ahadi S, Yasaei Z, Bazgir A. A clean and one-pot synthesis of spiroindoline-pyranopyrazoles. Journal of Heterocyclic Chemistry. 2010;47(5):1090-1094.

22. Aryanasab F, Ziyaei AH, Mohammad SR. Dithiocarbamate as an efficient intermediate for the synthesis of 2-amino-1,3,4-thiadiazoles in water. Tetrahedron Lett. 2010;51(5):790-792.

23. Moghaddam FM, Kiamehr M, Khodabakhshi MR, et al. A new domino Knoevenagel-hetero-Diels-Alder reaction: an efficient catalyst-free synthesis of novel thiochromone-annulated thiopyranocoumarin derivatives in aqueous medium. Tetrahedron. 2010;66(45):8615-8622.

24. Kolla SR, Lee YR. EDTA-catalyzed synthesis of 3,4-dihydroquinoxalin-2-amine derivatives by a three-component coupling of one-pot condensation reactions in an aqueous medium. Tetrahedron. 2010;66(46):8938-8944.

25. Hardin Narayan AR, Sarpong S. Remarkable facilitation of hetero-cycloisomerizations with water and other polar protic solvents: metal-free synthesis of indolizines. Green Chem. 2010;12(9):1556-1559.
26. Gawande MB. Current Trends in Aqueous Mediated Organic Synthesis. Organic Chem Curr Res. 2014;3:e134

27. Butler RN, Coyne AG. Organic synthesis reactions on-water at the organic-liquid water interface. Org Biomol Chem. 2016;14(42):99459960

28. García-García P, Moreno JM, Díaz U, et al. Organic-inorganic supramolecular solid catalyst boosts organic reactions in water. Nat Commun. 2016;7:10835.

29. Alaoui S, Driowya M, Demange L, et al. Ultrasound-assisted facile one-pot sequential synthesis of novel sulfonamide-isoxazoles using cerium (IV) ammonium nitrate (CAN) as an efficient oxidant in aqueous medium. Ultrason Sonochem. 2018;40(Pt A):289-297.

30. Dilauro G, Dell'Aera M, Vitale P, et al. Unprecedented Nucleophilic Additions of Highly Polar Organometallic Compounds to Imines and Nitriles Using Water as a Non-Innocent Reaction Medium. Angew Chem Int Ed Engl. 2017;56(34):10200-10203. 